\title{
UM ENCONTRO COM VIGOTSKI: 7 AULAS SOBRE OS FUNDAMENTOS DA PEDOLOGIA PROFERIDAS NA RÚSSIA E SUA TRADUÇÃO PARA O BRASIL
}

\section{A MEETING WITH VIGOTSKI: 7 LESSONS ABOUT THE PEDOLOGY FUNDAMENTALS PRONOUNCED IN RUSSIAN AND ITS TRANSLATE TO BRAZIL}

\author{
CAMILA FERREIRA DA SILVA ${ }^{1}$ \\ ORCID: https://orcid.org/0000-0002-2348-9350 \\ MICHELLE DE FREITAS BISSOLI ${ }^{2}$ \\ ORCID: https://orcid.org/0000-0002-2570-4392
}

\begin{abstract}
VIGOTSKI, Lev Semionovich. Sete aulas de L. S. Vigotski sobre os fundamentos da pedologia. Organização [e tradução]: Zoia Prestes e Elizabeth Tunes; tradução: Cláudia da Costa Guimarães Santana. Rio de Janeiro: E-Papers, 2018. 176p.
\end{abstract}

Desde a década de 1980, as ideias e constructos teóricos e metodológicos de Lev Semionovitch Vigotski têm povoado o cenário acadêmico brasileiro (SILVA; DAVIS, 2004) ${ }^{3}$, especialmente nas áreas da Educação e da Psicologia, mas também em áreas afins ao seu trabalho, como a Linguística, a Literatura, as Artes, entre outras. Nos mais de trinta anos que se passaram desde as primeiras traduções, publicações e apropriações dos escritos de Vigotski no Brasil, é possível afirmar que sua vida e obra são bastante conhecidas e disseminadas no âmbito da comunidade científica nacional. Contudo, o contexto no qual Vigotski produziu e publicou suas obras no seu país de origem - marcado pelas transformações sociais e políticas do período stalinista na União Soviética e pelas implicações de tais transformações no universo da produção cultural, acadêmica e científica - exerceu um impacto significativo sobre a difusão do pensamento deste psicólogo, tanto em solo soviético quanto em solo estrangeiro, impacto este que nos interessa e serve aqui de antessala para tratarmos da mais nova tradução de Vigotski no Brasil: o livro "Sete aulas de L. S. Vigotski sobre os fundamentos da pedologia", organizado por Zoia Prestes e Elizabeth Tunes e traduzido a seis mãos pelas próprias organizadoras juntamente com Cláudia da Costa Guimarães Santana.

Sendo Vigotski um dos maiores pensadores soviéticos do século XX, com obras traduzidas, editadas e publicadas nas mais diferentes línguas, alguns elementos merecem destaque no exercício de

\footnotetext{
${ }^{1}$ Professora Adjunta da Universidade Federal do Amazonas (UFAM); Professora Permanente do Programa de Pós-Graduação em Educação (PPGE/UFAM). Manaus, AM, Brasil. < ferreira.camilasilva@gmail.com>

${ }^{2}$ Professora Associada da Universidade Federal do Amazonas (UFAM); Professora Permanente do Programa de PósGraduação em Educação (PPGE/UFAM). Manaus, AM, Brasil. <mibissoli@yahoo.com.br>

3 O marco aqui é a tradução e publicação no Brasil de "A formação social da mente" em 1984. 
compreender as numerosas distorções e interpretações equivocadas de suas ideias, tais como: a perseguição interposta aos intelectuais na União Soviética recaiu sobre Vigotski e suas obras sofreram adulterações, cortes e censuras, chegando a ficarem proibidas na URSS por vinte anos; as publicações em outros países ficaram predominantemente a cargo das interpretações e sínteses dos seus tradutores e editores; no caso do Brasil, grande parte dos seus trabalhos foi traduzida do inglês para o português por intermédio de estudiosos norte-americanos e apresenta um caráter resumido (PRESTES, 2010; PRESTES; TUNES, 2011). Estas questões acompanhadas da morte prematura de Vigotski e do fato de que grande parte de seus textos foi redigida e publicada postumamente com base em estenografias de aulas e palestras, amplificam a relevância de se compreender as condições de feitura e difusão de seu pensamento.

O livro "Sete aulas de L. S. Vigotski sobre os fundamentos da pedologia" acaba de ser publicado no Brasil e merecem destaque: o fato de que os manuscritos que deram origem a este livro são oriundos de aulas proferidas por Vigotski no fim de sua vida e que permaneceram guardados por mais de sessenta anos nos arquivos da família de um de seus alunos, Serapion Alekseevitch Korotaiev (TUNES; PRESTES, 2018); o ineditismo do texto em português, com exceção apenas da quarta aula que foi publicada em 2010 pela revista Psicologia USP'; bem como o trabalho minucioso e cuidadoso das tradutoras e organizadoras, que, inclusive, estabeleceram parceria com os familiares de Vigotski para os estudos, pesquisas e traduções que balizaram a obra, especialmente com sua neta Elena Kravtsova (PRESTES; TUNES, 2018). Qual seria o impacto, afinal, da tradução dessas aulas para a língua portuguesa e de sua publicação no Brasil? Este questionamento constitui o fio condutor da análise que empreendemos nesta resenha.

As organizadoras Zoia Prestes ${ }^{5}$ e Elizabeth Tunes $^{6}$ decidiram agregar outros materiais às sete aulas em questão e, com isso, apresentam ao público brasileiro uma obra capaz não somente de trazer à tona o pensamento de Vigotski por meio de sua preleção, mas também de, por um lado, situar o contexto histórico e político no qual este psicólogo trabalhou, pesquisou, produziu e publicou seus escritos e, por outro, apresentar uma crítica encomendada que é frequentemente citada na literatura. Desse modo, a própria organização da obra é reveladora de como estas frentes se conectam. O livro é dividido, para além de sua breve apresentação, em três partes, nomeadamente: 1) "O bom, o mau e o feio" abre o livro e é assinada pelas próprias organizadoras, nesta parte o trabalho de Vigotski é situado em meio ao cenário soviético da década de 1930 correspondente a uma fase de perseguição, inclusive a intelectuais, no regime de Stalin, as organizadoras trazem, ainda, neste espaço breves informações acerca das duas próximas partes do livro, possibilitando ao leitor um entendimento exordial e, sobretudo, situacional com relação às condições de produção tanto das sete aulas quanto da crítica que as segue; 2) "Fundamentos da Pedologia de L. S. Vigotski" constitui a segunda parte e é aqui que estão traduzidas as sete aulas que dão nome à obra; e, por fim, 3) "As falsas ideias de L. S. Vigotski na pedologia" traz a crítica encomendada e assinada por Eva Izrailevna Rudniova. Centraremo-nos, pois, a partir de agora na segunda e terceira partes do livro.

De modo geral, as sete aulas em questão nos colocam em contato com um Vigotski professor: seu tom coloquial, sua maturidade e preocupações pedagógicas ligadas à clareza de suas ideias e à compreensão por parte de seus estudantes e seu constante exercício de explicar por meio de exemplos constituem elementos que nos permitem perceber traços de sua atuação enquanto docente no Departamento de Pedologia do Instituto A. I. Guertsen de Leningrado. Ainda em uma mirada mais geral, é possível ratificar que o conteúdo dessas aulas acaba por aprofundar e lançar luz a debates em torno de questões fulcrais que têm povoado as pesquisas no âmbito da Teoria Histórico-Cultural no Brasil.

\footnotetext{
${ }^{4}$ Disponível em: http://www.revistas.usp.br/psicousp/article/view/42022/45690.

${ }^{5}$ Zoia Prestes é graduada e mestre em Pedagogia e Psicologia Pré-Escolar pela Universidade Estatal de Pedagogia de Moscou e doutora em Educação pela Universidade de Brasília. Atualmente é professora da Faculdade de Educação da Universidade Federal Fluminense (informações retiradas de seu currículo lattes).

${ }^{6}$ Por sua vez, Elizabeth Tunes é graduada em Psicologia pela Universidade de Brasília e possui mestrado e doutorado em Psicologia pela Universidade de São Paulo. Atualmente é pesquisadora associada da Universidade de Brasília e professora do Centro Universitário de Brasília (informações retiradas de seu currículo lattes). 
$\mathrm{Na}$ primeira aula, intitulada "O objeto da pedologia", Vigotski esclarece desde o início que a Pedologia é a ciência que se ocupa do desenvolvimento da criança, sendo este o seu objeto direto e imediato. Tal afirmação é o ponto de partida para o autor desconstruir a ideia de desenvolvimento como um processo linear ou organizado temporalmente de modo simples. A complexidade que envolve o desenvolvimento da criança é explicitada por Vigotski por meio da diferenciação da contagem cronológica do tempo (idade biológica) com relação ao ritmo e ao nível do desenvolvimento (idade pedológica). Vigotski discute, nesta aula, as idades como ciclos cujos tempos e conteúdos são bastante específicos, demandando da Pedologia uma investigação que considere que o desenvolvimento infantil é marcado por processos progressivos e reversos, sendo a criança qualitativamente diferente do adulto tanto em sua estrutura orgânica quanto em sua personalidade. Um apelo metodológico marca constantemente esta primeira aula, posto que Vigotski alerta para as implicações metodológicas da compreensão do objeto da Pedologia, o que acaba por servir de introdução e conexão com a segunda aula, "A definição do método da pedologia". Nesta segunda aula evidente se torna a defesa que o autor realiza de um método próprio para a investigação pedológica, o qual é definido pelas especificidades do objeto desta ciência e que se distingue a) por ser um método global de estudo da unidade do desenvolvimento, b) pelo seu caráter clínico e ainda c) por se constituir um método genérico comparativo.

$\mathrm{Na}$ sequência, temos a terceira e a quarta aulas, que também apresentam entre si um caráter de complementaridade. A terceira aula, "O estudo da hereditariedade e do meio na pedologia", parte do pressuposto de que, sendo o desenvolvimento um processo dinâmico, ele se constitui em uma unidade que sofre influências tanto hereditárias quanto do meio. Nesta aula, Vigotski demonstra de modo mais aprofundado o papel da hereditariedade no desenvolvimento da criança e a variação do peso do componente hereditário ao longo do tempo. Tal variação é determinada, ainda, pelas características das funções psíquicas sob análise pedológica. Enquanto nas funções elementares, a hereditariedade exerce maior influência; nas funções superiores, a hereditariedade não se manifesta tão diretamente, tendo em vista que estas são fruto do desenvolvimento cultural. $\mathrm{O}$ pensador esclarece que o desenvolvimento contém sempre, em uma unidade, aspectos hereditários e do meio. A quarta aula, por sua vez - "O problema do meio na pedologia" -, aprofunda estas questões e se ocupa mais detidamente em evidenciar o papel do meio como fonte do desenvolvimento "[...] das formas de atividade e das características superiores especificamente humanas" (VIGOTSKI, 2018, p. 90). Vigotski traz, aqui, o conceito de "vivência", que se refere à relação entre as particularidades psicológicas da criança e os fatos objetivos com que ela se defronta. Explica, nesse bojo, que o meio se modifica para a criança a cada degrau etário (no âmbito da idade pedológica), na medida em que o nível de compreensão ou a atribuição de sentido ao que acontece se altera na consciência da criança.

O último bloco de aulas é responsável por aprofundar o debate em torno do desenvolvimento das crianças. A quinta aula, intitulada "Leis gerais do desenvolvimento psicológico da criança", inicia esclarecendo que o homem é um sistema único, porém heterogêneo e complexo, entendimento que auxilia no exercício que Vigotski empreende em torno da explicitação dos processos de mudanças, ligações, isolamento e reestruturações das funções psicológicas no âmbito do desenvolvimento da personalidade consciente da criança. $\mathrm{O}$ autor ratifica que cientificamente não se justifica a separação entre desenvolvimento psicológico e físico e, a partir disso, na sexta e na sétima aulas, respectivamente, "Leis gerais do desenvolvimento físico da criança" e "As leis do desenvolvimento do sistema nervoso", Vigotski se ocupa da demonstração das mudanças das relações de dependência no interior dos sistemas endócrino e nervoso, apontando que, no interior de cada sistema e entre eles, existem relações complexas, processos de evolução e involução, e, sobretudo, um intercâmbio entre todos os sistemas. O desenvolvimento é explicitado como um processo marcado pela alteração das relações entre os sistemas orgânico e psicológico, "sendo a alteração das relações internas do todo a nova organização que a criança apresenta em cada novo degrau etário" (VIGOTSKI, 2018, p. 146).

A última parte do livro traz a tradução de uma brochura, de autoria de Eva Izrailevna Rudniova, a quem fora encomendada uma crítica ao trabalho de Vigotski sobre a Pedologia. Vigotski é acusado incessantemente por Rudniova de desenvolver uma Pedologia mecanicista com base em testes classistas, sustentada por um ecletismo teórico, o qual ela ataca por entender que se devia a uma espécie 
de sobreposição de "teorias psicológicas estrangeiras" em detrimento de uma teoria propriamente soviética. Vigotski é chamado de "antimarxista" e "antileninista", o primeiro em função, segundo Rudniova, da utilização de escritos reacionários de cientistas burgueses e fascistas, e o segundo porque ela entendia que a teoria de Vigotski era nociva à escola e previa a morte gradual desta instituição. $\mathrm{O}$ tom irônico e o desrespeito marcam o texto de Rudniova e, em sentido mais analítico, evidentes se tornam as contradições com relação ao que sua crítica aponta e ao que Vigotski de fato defendia - as organizadoras deste livro chegam a questionar se teria sido mesmo Rudniova a autora da crítica em questão ou se ela teria sido obrigada a assinar o texto elaborado por um funcionário burocrático de Stalin.

Acreditamos, ademais, que a decisão das organizadoras de incluir tal crítica nesta obra, logo após as aulas de Vigotski, cumpre um papel quase que didático: o leitor acaba sendo incumbido da tarefa de descobrir por si mesmo a pertinência - ou a falta dela (TUNES; PPRESTES, 2018) - da crítica de Rudniova, uma vez que ele próprio teria acabado de ler as sete aulas e seria capaz de confrontar as acusações presentes nesta crítica com as ideias que Vigotski apresenta e defende nas suas aulas.

Com a tradução e publicação de um material tão rico como o que compõe a obra aqui analisada, Zoia Prestes e Elizabeth Tunes trazem para o público brasileiro uma tradução que se destaca pela qualidade e preocupação de exposição das tomadas de decisões próprias desse processo, e ainda um conjunto de textos que auxilia o leitor a compreender tanto o pensamento de Vigotski quanto o contexto de produção e de difusão de suas ideias. A publicação, em 2018, das sete aulas de Vigotski insere-se, pois, no cenário de ampliação das discussões e pesquisas acerca de temas e objetos que têm dialogado há mais de três décadas com as ideias e constructos vigotskianos no Brasil e de consolidação dos grupos de pesquisadores que têm se dedicado a desenvolver suas investigações no âmbito da Teoria HistóricoCultural.

Nesse sentido, e aqui retomando nosso questionamento preambular em torno do impacto desta obra no Brasil, o livro representa uma contribuição original para o aprofundamento do debate sobre o pensamento de Vigotski, pensador que tem ocupado uma posição de destaque nos cursos de formação de professores e nas pesquisas nas áreas de Educação e Psicologia no país, ao passo que reacende o debate acerca de conceitos-chave vigotskianos e que vinham sendo utilizados por intermédio das muitas traduções marcadas pelos atravessamentos históricos que apontamos inicialmente.

\section{REFERÊNCIAS}

PRESTES, Zoia; TUNES, Elizabeth. Notas biográficas e bibliográficas sobre L. S. Vigotski. Universitas: Ciências da Saúde, Brasília, v. 9, n. 1, p. 101-135, jan./jun. 2011.

PRESTES, Zoia; TUNES, Elizabeth. Apresentação. In: VIGOTSKI, Lev Semionovich. Sete aulas de L. S. Vigotski sobre os fundamentos da pedologia. Organização [e tradução]: Zoia Prestes e Elizabeth Tunes; tradução: Cláudia da Costa Guimarães Santana. Rio de Janeiro: E-Papers, 2018. p. 5-6.

SILVA, Flávia Gonçalves; DAVIS, Claudia. Conceitos de Vigotski no Brasil: produção divulgada nos cadernos de pesquisa. Cadernos de Pesquisa, v. 34, n. 123, p. 633-661, set./dez. 2004.

TUNES, Elizabeth; PRESTES, Zoia. O bom, o mau e o feio. In: VIGOTSKI, Lev Semionovich. Sete aulas de L. S. Vigotski sobre os fundamentos da pedologia. Organização [e tradução]: Zoia Prestes e Elizabeth Tunes; tradução: Cláudia da Costa Guimarães Santana. Rio de Janeiro: E-Papers, 2018. p.7-16.

VIGOTSKI, Lev Semionovich. Sete aulas de L. S. Vigotski sobre os fundamentos da pedologia. Organização [e tradução]: Zoia Prestes e Elizabeth Tunes; tradução: Cláudia da Costa Guimarães Santana. Rio de Janeiro: E-Papers, 2018. 
Submetido: 22/11/2019

Aprovado: 26/05/2020 